\title{
Intravesical Liposome and Antisense Treatment for Detrusor Overactivity and Interstitial Cystitis/Painful Bladder Syndrome
}

\author{
Pradeep Tyagi, ${ }^{1}$ Mahendra P. Kashyap, ${ }^{1}$ Naoki Kawamorita, ${ }^{1}$ Tsuyoshi Yoshizawa, \\ Michael Chancellor, ${ }^{2}$ and Naoki Yoshimura ${ }^{1}$ \\ ${ }^{1}$ Department of Urology, University of Pittsburgh, PA 15213, USA \\ ${ }^{2}$ Department of Urology, William Beaumont School of Medicine, Royal oak, MI 48073, USA \\ Correspondence should be addressed to Pradeep Tyagi; prt18@pitt.edu
}

Received 18 July 2013; Accepted 24 October 2013; Published 16 January 2014

Academic Editors: S. Mingmalairak, T. W. Stone, and S.-N. Wu

Copyright (C) 2014 Pradeep Tyagi et al. This is an open access article distributed under the Creative Commons Attribution License, which permits unrestricted use, distribution, and reproduction in any medium, provided the original work is properly cited.

\begin{abstract}
Purpose. The following review focuses on the recent advancements in intravesical drug delivery, which brings added benefit to the therapy of detrusor overactivity and interstitial cystitis/painful bladder syndrome (IC/PBS). Results. Intravesical route is a preferred route of administration for restricting the action of extremely potent drugs like DMSO for patients of interstitial cystitis/painful bladder syndrome (IC/PBS) and botulinum toxin for detrusor overactivity. Patients who are either refractory to oral treatment or need to mitigate the adverse effects encountered with conventional routes of administration also chose this route. Its usefulness in some cases can be limited by vehicle (carrier) toxicity or short duration of action. Efforts have been underway to overcome these limitations by developing liposome platform for intravesical delivery of biotechnological products including antisense oligonucleotides. Conclusions. Adoption of forward-thinking approaches can achieve advancements in drug delivery systems targeted to future improvement in pharmacotherapy of bladder diseases. Latest developments in the field of nanotechnology can bring this mode of therapy from second line of treatment for refractory cases to the forefront of disease management.
\end{abstract}

\section{Introduction}

Intravesical therapies have demonstrated varying degrees of efficacy and safety in treatment of interstitial cystitis/painful bladder syndrome (IC/PBS) [1] and overactive bladder OAB [2]. Pharmacotherapy by this route provides high local drug concentrations in the bladder with low risk of systemic side effects [3]. Conventional therapies for $\mathrm{OAB}$ and detrusor overactivity (DO), either neurogenic or idiopathic, have limited efficacy and acceptability. Anticholinergic medications, which are currently the mainstay of the treatment of $O A B$, are not always effective and often have undesirable side effects such as dry mouth and constipation [4]. Therefore, search for alternative therapies directed against local targets with fewer side effects is encouraged.

The IC/PBS syndrome is characterized by pelvic pain and urinary storage symptoms (e.g., urinary urgency and frequency). The O'Leary-Sant symptom and problem score (interstitial cystitis symptom index (ICSI) and problem index (ICPI)) is recognized as one of the most reliable and valid instruments to identify the extent of bothersome symptoms and the most prominent voiding and painful symptoms in IC/PBS patients $[5,6]$. Pentosan polysulfate, PPS, is a synthetic sulphated polysaccharide and is the only approved oral drug for IC/PBS, but it requires daily administration for 6 months before any benefit accrues for the patients $[7,8]$. Less than one-tenth of oral dose is excreted into the urine of IC/PBS patients, which is considered to replenish the damaged glycosaminoglycan GAG layer and reduce the influx of potassium back into bladder from urine.

Orally administered agents are often unable to create effective luminal drug concentration due to low urinary excretion of drugs, which justifies bladder instillation. Replacement of GAG layer by intravesical administration of hyaluronic acid has been successfully tried in IC/PBS patients [9]. Intravesical therapy also holds the potential to facilitate 
the separation of therapeutic actions from side effects by involving a diverse array of novel chemical, pharmacological, and formulation strategies. However, drug delivery by intravesical route is constrained by the impermeability of the urothelium, short duration of action, and the need for frequent administration.

The urinary bladder lining is the most impermeable barrier in the human body $[10,11]$. Therefore, therapies delivered directly to the bladder lumen have limited opportunity for systemic distribution, which typically leads to fewer side effects. In addition, the mechanisms for locally delivered therapies can be independent of existing oral therapies, and in some cases, an additive effect can provide compelling comarketing opportunities [12]. We will review the current understanding of urothelium structure and role of intravesical drug delivery in unmasking the pharmacological function of different receptors expressed on its luminal surface.

\section{Urothelium}

Recent investigations have revealed that the urothelium is not just a physical barrier between blood and urine but can express a host of receptors having a functional significance in micturition reflex. The recent identification of a cannabinoid, nicotinic, neurokinin receptors and potassium ion channels in urothelium [13-16] have revealed the role of urothelium as an excitable cell layer in bladder that responds to stretch and convey messages to underlying afferents in bladder. There is also mounting evidence to demonstrate expression of adrenergic, bradykinin, and transient receptor potential (TRP) receptors in urothelium and in proximity of afferent nerves $[17,18]$. Urothelium is the primary nonneuronal source for the release of molecules such as adenosine triphosphate (ATP), acetylcholine, and nitric oxide, which are known to affect micturition $[19,20]$. Intravesical therapy can be used to unravel the pharmacology of these receptors and paracrine messengers released from urothelium $[21,22]$.

\section{Muscarinic Receptors}

It is widely accepted that oral antimuscarinics act on muscarinic receptors in the detrusor for managing the symptoms of $\mathrm{DO}$ and $\mathrm{OAB}$. Conventional wisdom largely ignores the role of muscarinic receptors expressed on urothelium [23]. Muscarinic receptors expressed on urothelium are believed to be involved in afferent signaling for micturition [23]. The afferent signals are believed to be generated from the basal nonneuronal acetylcholine released during the storage phase from urothelium to enhance the myogenic contractile activity of the detrusor $[19,20]$.

Theoretically speaking, not only can receptors expressed on the urothelium be influenced by antimuscarinics via the bloodstream, but also few selected antimuscarinics and their active metabolites can affect the muscarinic receptors from the luminal side following their excretion into urine [12]. Alternative mode of action for two antimuscarinic drugs, trospium and solifenacin, was demonstrated by our group $[21,22]$. DO in the rat was mimicked by intravesical carbachol
[21, 22]. Urine collected from human volunteers who took trospium and solifenacin was then instilled into rat bladder to determine the effect of the drug fraction excreted into urine. Therefore, intravesical therapy can assist in elucidating the yet unexplored mechanisms for improvement of OAB symptoms by antimuscarinics.

\section{Liposomes}

Liposomes were earliest prototype of nanoparticles (particles with one of the dimensions in nanometers) that are described as lipid vesicles composed of concentric phospholipid bilayers enclosing an aqueous interior $[24,25]$. The lipid vesicles comprise either one or several aqueous compartments delineated by either one (unilamellar) or several (multilamellar) phospholipid bilayers [26]. Liposomes have been widely studied as drug carriers for a variety of chemotherapeutic agents (approximately 40,000 scientific articles have been published on the liposomes use so far) [25, 27]. Liposomes improved the delivery of chemotherapeutic agents by altering pharmacokinetics and reducing toxicity $[26,28,29]$. The success of liposomes in the clinic has been attributed to the nontoxic nature of the lipids used in their formulation.

\section{Empty Liposomes}

Empty liposomes itself can act as a topical healing agent and same has been demonstrated in treatment of dry eye $[30,31]$. Either empty or with entrapped drugs, liposomes have also been used in ophthalmology to ameliorate keratitis, corneal transplant rejection, uveitis, endophthalmitis, and proliferative vitreoretinopathy [32]. These reports encouraged investigation of empty liposomes as a therapeutic agent for bladder injury. Interaction of liposomes with cultured urothelium cells suggested that liposomes can be adsorbed and be endocytosed [33]. Previous studies showed that binding of large multilamellar liposomes to the bladder cells was stronger than of sonicated small size liposomes [34, 35].

5.1. Preclinical Studies. A rat model of bladder injury induced by protamine sulfate [36] was used to asses efficacy of empty liposomes. Instillation of liposomes protected bladder irritation induced by protamine sulfate instillation into rat bladder [37] (Figure 1). In earlier study, empty liposomes were used as controls against capsaicin delivery study, which reported tolerance of empty liposomes in uninjured bladder [38]. Bladder tolerance was investigated by cystometry and histology [38].

Physiological effect of liposomes on bladder irritation model induced by protamine sulfate was studied in separate studies $[39,40]$. Cystometric studies involved bladder injury induced by infusion of protamine sulfate for an hour followed by irritation caused by infusion of high concentration of potassium chloride solution [39, 40]. Post-treatment of liposomes demonstrated the protective effect in this model $[39,40]$, which involved coadministration of liposomes with potassium chloride to mimic the clinical disease condition. The comparative efficacy of liposomes was evaluated against 


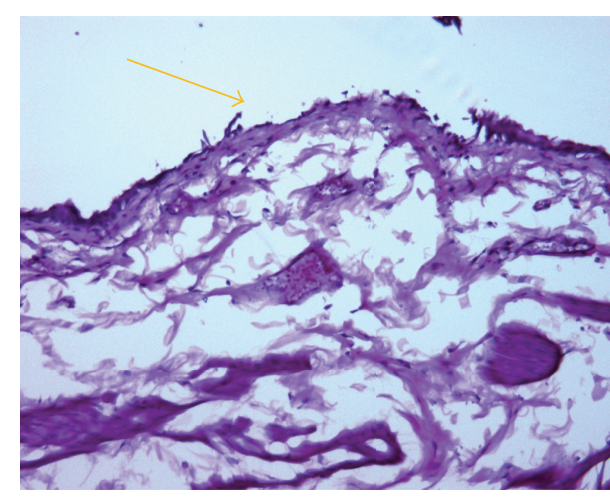

(a)

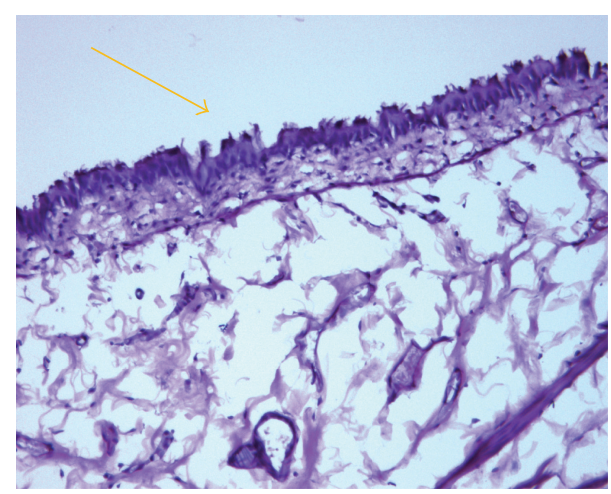

(b)

FIGURE 1: Protective effect of liposomes evaluated by histology in rat bladder injured by protamine sulfate. Focal loss of apical layer and ulcerated areas were noted in saline treated rats (a). Liposome post-treatment protected rats from ulceration induced by PS as evident from photograph in (b) taken on bladder harvest at $8 \mathrm{~h}$ after liposome instillation.

FDA approved therapies of dimethyl sulphoxide (DMSO) and intravesical instillation of PPS [1].

Clinically, DMSO (RIMSO-50) is the only FDA approved intravesical treatment for PBS/IC, [41] but off-label instillation of PPS has also been pursued [42]. The efficacy of various treatments was evaluated in chemically induced bladder hyperactivity in rats by sequential infusion of protamine sulfate and potassium chloride. Bladder reflex activity of female Sprague-Dawley rats before and after treatment was evaluated by continuous cystometry under urethane anaesthesia $(1.0 \mathrm{~g} / \mathrm{kg})$. Intravesical liposomes were effective in doubling the intercontractile interval (ICI) compared with PPS, while acute instillation of DMSO failed to produce any protective effect in this animal model [43].

Recently, Lee et al. [44] further improved this model of DO induced by intravesical infusion by combining it with systemic metabolic alteration through fructose feeding. Metabolic syndrome created by feeding of fructose to rats can lead to DO and urination frequency [44]. Cystometric bladder capacity of fructose fed rats can be further decreased by instillation of acidic ATP solution, which provokes reflex micturition via afferent noise. Evidence suggests that increased expression or release of neurotransmitters in the mucosal layer of the bladder can generate afferent noise via C-fiber pathway and result in DO [45]. Compared to infusion with normal saline, ATP solution decreased bladder capacity and increased phasic contractions. Addition of liposomes to the ATP solution partially reversed the ATP solutioninduced response [46]. Capsaicin induced desensitization also blunted the provocation of ATP in this model to demonstrate the role of afferent noise via C-fibers.

5.2. Clinical Studies. Encouraged by the exciting preclinical efficacy of empty liposomes as a therapeutic agent for intravesical therapy of IC/PBS, Chuang et al. recently published the clinical safety and efficacy of liposomes in IC/PBS patients [47]. In an open label prospective study on 24 IC/PBS patients, the effect of intravesical liposomes was compared against oral PPS. Patients were equally divided into the two treatment arms, administered either intravesical liposomes $(80 \mathrm{mg} / 40 \mathrm{cc}$ distilled water) once weekly or oral PPS (100 mg) 3 times daily for 4 weeks each. Ten possible responses to treatment were monitored at 3 time points, including baseline, and at weeks 4 and 8 .

Comparable efficacy of liposomes to oral PPS was demonstrated by statistically significant decreases in urinary frequency and nocturia in both treatment arms. Liposome treated patients showed statistically significant decreases in pain, urgency, and the O'Leary-Sant symptom score, with the effect being most profound on urgency. None of the treated patients in the study reported urinary incontinence, retention, or infection due to liposome instillation and there were no unanticipated adverse events and no significant worsening of symptoms during followup. Intravesical instillation of liposomes in IC/PBS patients was found to be safe with potential improvement after 1 course of therapy for up to 8 weeks. The study design was suboptimal, with lack of blinding and two treatment arms assigned to different routes of drug administration and regimen. Still once weekly liposome therapy was able to demonstrate efficacy comparable to thrice daily oral administration of PPS.

Subsequently, Lee et al. assessed the safety and efficacy of twice weekly administration of liposomes on IC/PBS symptoms [48]. Five patients were given twice a week treatment of liposomes for 4 weeks. The primary outcome was the change in the O'Leary-Sant symptom/problem score and O'LearySant total score from baseline to week 4 and week 8 . The O'Leary-Sant symptom/problem score, O'Leary-Sant total score, and pain score at the 4-week followup showed significantly greater improvement from baseline with biweekly instillation than once a week instillation. Tolerability of liposomes remains unchanged from once a week regimen to twice a week regimen. The followup at 8 weeks was also similar for both treatment regimens. The incidence of urinary incontinence, retention, or unanticipated adverse changes was not noted with any regimen. Intravesical liposomes appear to be a promising new treatment for IC/PBS and future large-scale placebo controlled studies are needed to verify these results from a pilot study. 


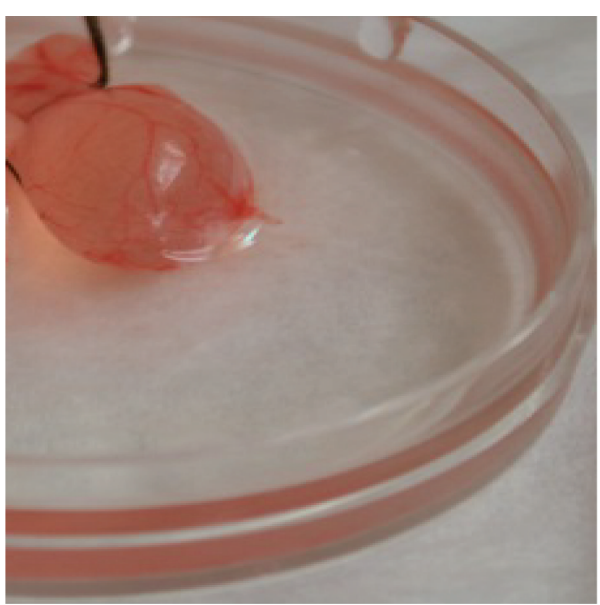

(a)
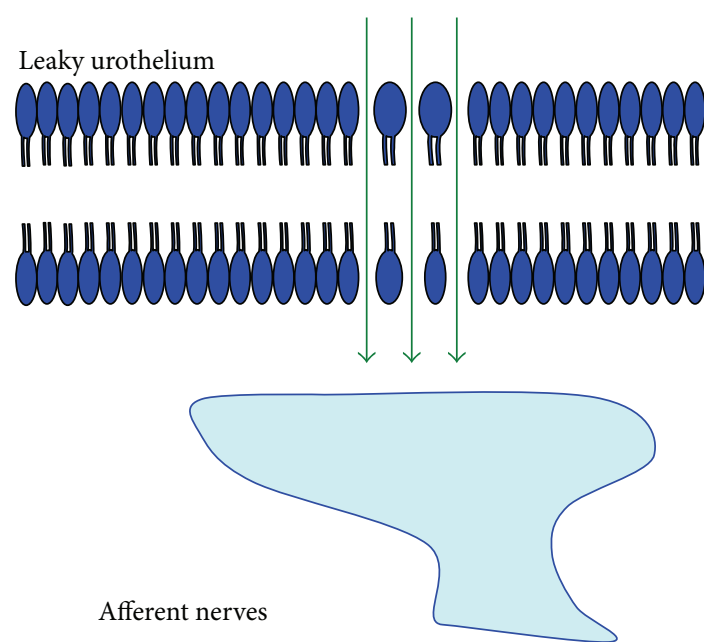

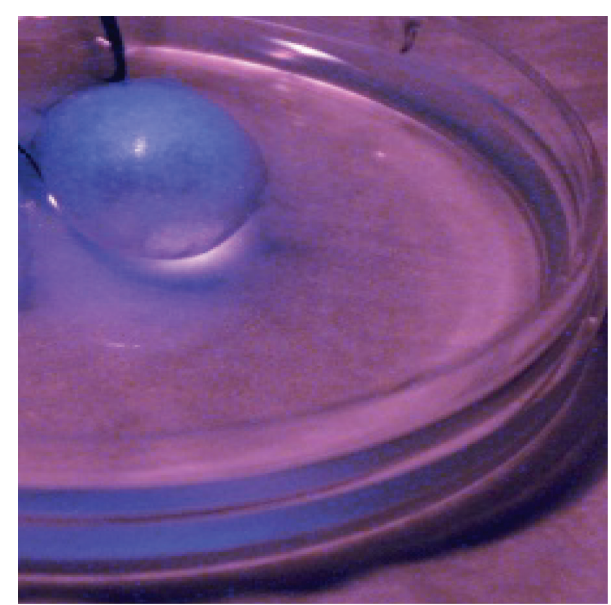

(b)
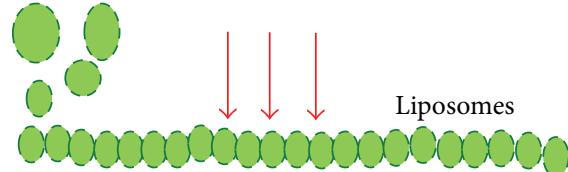

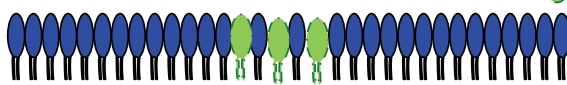
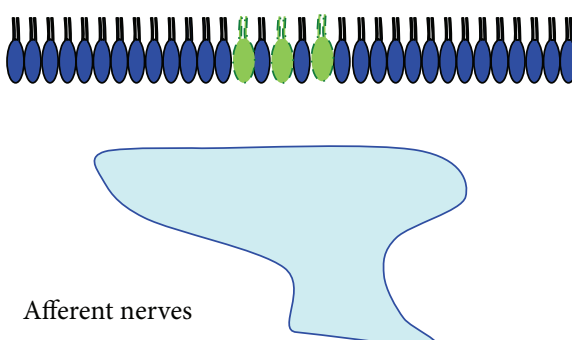

(c)

FIGURE 2: Ex vivo images of rat bladder taken in visible and near-infrared light indicate the coating formed by instilled liposomes on bladder surface. Liposomes carry a trace amount of near-infrared (NIR) lipophilic carbocyanine dye $1,1^{\prime}$-dioctadecyl-3,3,3 $3^{\prime}, 3^{\prime}$ tetramethylindotricarbocyanine iodide (DiR) that fluoresces on exposure to NIR light. Rat bladder filled with urine was tied at the base with thread prior to harvest. Liposomes coating the bladder surface are invisible in visible light photograph (a) but is indicated by blue colored coating on the bladder luminal surface in NIR light (b). NIR imaging in vivo can allow noninvasive repeat objective measurement for bladder residence time of instilled treatments. (c) Schematic illustration of liposome coating the bladder surface. Given the chemical affinity of phospholipids of instilled liposomes with lipids in cells lining the bladder surface, the liposomes form a protective film coating on the injured bladder lumen surface and assist in the repair of leaky and inflamed uroepithelium.

The exact mechanism of action for liposomes in IC/PBS remains to be established, but protective coating effect based on preclinical studies cannot be ruled out as illustrated in Figure 2.

\section{Liposomes as a Delivery Platform}

Not only is the lining of the urinary bladder the most impermeable tissue in the human body, but it is also the most compliant. As a bladder lining expands, additional membrane material is added to its cells to help retain impermeability [49]. Therefore, vesicular trafficking may provide a favorable environment for drug delivery and therefore it is worth investigating whether vesicle nature of liposomes can aid in improving the delivery of cargo across the bladder permeability barrier.

In the field of neurourology, instillation of neurotoxins into bladder is an accepted approach to achieve chemical neuromodulation of afferent neurotransmission underlying neurogenic bladder and IC/PBS [50]. Existing approaches of chemical neuromodulation by intravesical neurotoxins are suboptimal due to vehicle toxicity for capsaicin [51] or degradation of botulinum toxin (BoNT) in urine. Possible reasons underlying the lack of efficacy from BoNT instillation in bladder can be protein degradation by proteases and proteinases in urine, dilution in urine, or poor uptake of the BoNT solution into the urothelium.

Liposomes have been previously studied as a carrier of toxins to enhance efficacy at lower doses [52]. In the context of 

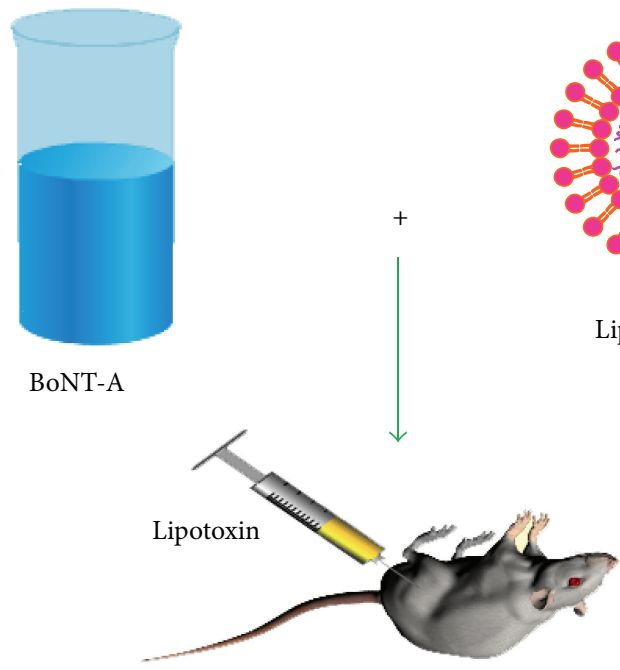

Intravesical instillation

FIGURE 3: Scheme for formulation of BoNT into liposomes for bladder instillation. Freeze dried BoNT is resuspended in distilled water and added to vials containing a desiccated liposomal preparation made of phospholipids. This reconstituted suspension is allowed to hydrate at room temperature for 30-60 min before instillation.

toxins instilled in the bladder, fat-soluble neurotoxin such as capsaicin can be integrated into the phospholipid bilayer [38] and water-soluble neurotoxin such as BoNT can be protected inside the aqueous compartment(s) of liposomes delimited by the phospholipid bilayer(s) [53] (Figure 3). Cystoscope guided injections are the current standard practice in the clinic for administering BoNT to the bladder. But in recent years, studies have also assessed the potential for intravesical instillation of BoNT alone in animal models of bladder irritation [54].

Development of instillation as a mode for administering BoNT in patients will drastically bring down the cost of treatment for patients with refractory overactive bladder. Other groups have recently reported the use of DMSO for instillation of BoNT instead of injection [55]. DMSO does not afford the natural state of the BoNT as a protein and need to be formulated immediately before instillation. Dissolving BoNT in DMSO may not be advisable owing to concerns of BoNT uptake into the systemic circulation of patient. Moreover, biochemical studies have demonstrated that metalloproteolytic activity of the BoNT is strongly enhanced by the presence of lipid membranes [56].

Recent studies reaffirmed the potential of liposomes as a promising vehicle for delivery of neurotoxins to the bladder $[38,53]$. The transport of BoNT into urothelium from liposomes was confirmed by detection of its unique effect on neurotransmitters and proteolysis of synaptosomalassociated protein SNAP-25 through immunohistochemistry [53]. The protection of BoNT entrapped inside liposomes from degradation in urine without compromising efficacy was demonstrated by attenuation of acetic acid induced bladder irritation in rats [53]. Similar results were obtained in preclinical studies with liposomes encapsulating capsaicin [38].
Liposomes have proven themselves as biocompatible delivery agents in the bladder.

\section{Intravesical Antisense Therapeutics}

The term "antisense" therapeutics emerged from seminal studies done 4 decades using a short synthetic oligonucleotide for sequence-specific gene silencing [57]. Gene silencing involves introduction of short strands of DNA (termed as antisense) with sequences complementary to the mRNA encoding a particular gene inside the cell with the intent to block gene expression through either translational inhibition or enzymatic cleavage of the mRNA target [3].

Oligonucleotide ODN binds specifically and strongly to the mRNA target through Watson-Crick base pairing. ODN can be basically categorized into those that direct cleavage of the target mRNA as caused by small interfering RNAs (siRNAs) and those that alter mRNA translation without causing mRNA cleavage. Recent discovery of small interfering RNAs (siRNAs) and the elucidation of the RNA interference (RNAi) pathway has also brought a sea change in the control of posttranscriptional gene expression. siRNA takes advantage of endogenous cellular pathways to potently silence the expression of specific genes (Figure 4).

Antisense mechanism is a promising approach for developing therapeutics based on rational gene-based drug design. Antisense therapeutics have been under clinical investigation for more than 30 years [58]. However, drug development of this approach has been hampered by inefficient intracellular delivery and cellular uptake of the ODN. The translation of basic antisense research into therapeutics is also impeded by intracellular stability of ODN and potential for "off-target" gene silencing, immunostimulation, and other side effects.

A vast array of chemical modifications to ODN has been developed to overcome the therapeutically limiting features by altering internucleotide phosphate linkages, backbone sugars, or nucleobases. One such modified ODN is peptide nucleic acid, which replaces phosphodiester bond between nucleobases with a peptide bond. Replacement of phosphodiester bond by a phosphorothioate linkage is another method to improve the stability of ODN against nucleases.

Great progress has been made in translating antisense research into clinical therapies based on local injection into eye [58]. The field recently progressed further with a systemic injection therapy for treating familial hypercholesterolemia [59]. Antisense therapeutics have been used for exon skipping to optimize the functionality of a truncated dystrophin protein in dog model of Duchenne muscular dystrophy [60].

Nevertheless, applied research for bladder diseases has lagged behind, considering that the anatomical architecture of bladder provides ease of local administration with restricted systemic side effects due to lower serum uptake of antisense ODN. Bladder instillation of antisense ODN or their chemically modified mimics can therefore be an efficient means to control the expression of therapeutically relevant genes. Antisense agents can also be used to elucidate the role of newly discovered genes in bladder function. 


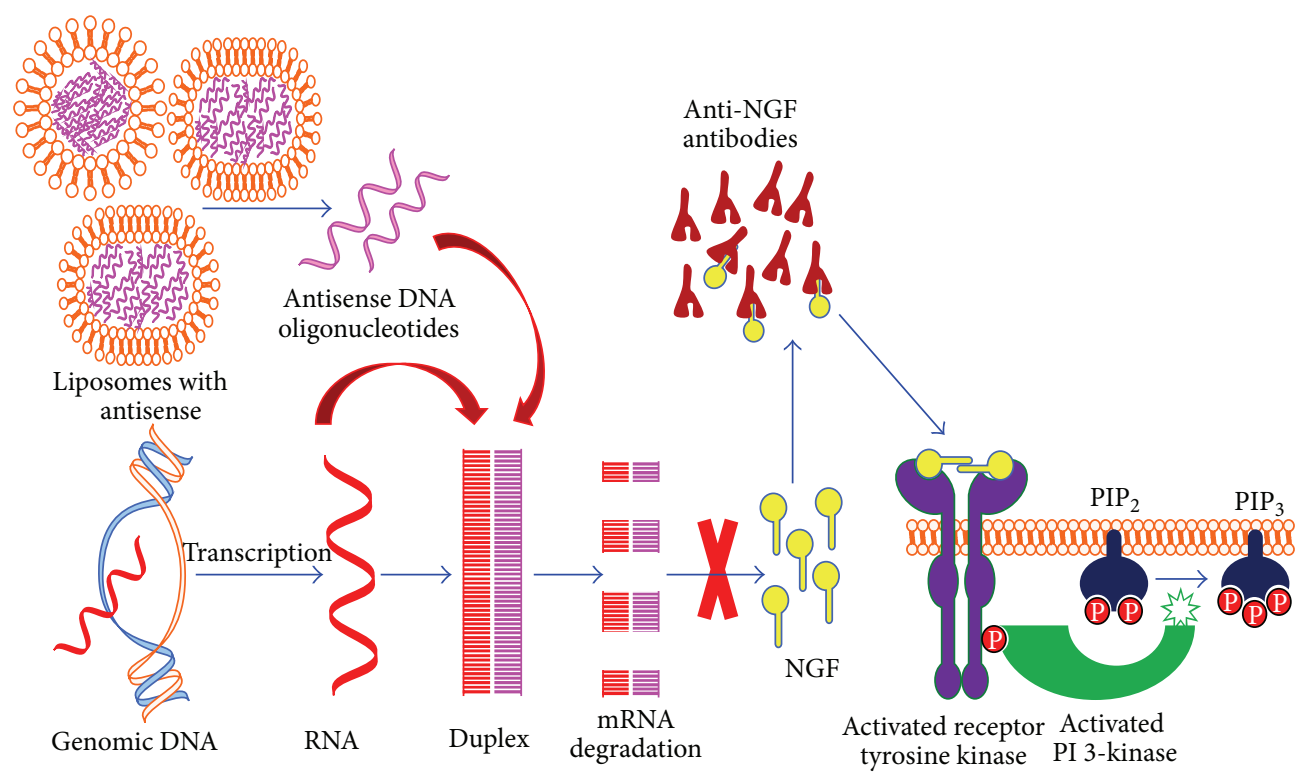

FIGURE 4: Illustration of mechanisms for blocking NGF expression by either NGF antibodies or downregulation of NGF mRNA expression. NGF antibody sequesters the freely available NGF and prevents it from binding with the cognate TrkA receptors. NGF antisense selectively binds with NGF mRNA inside the cells to block the translation of corresponding mRNA. siRNA takes advantage of endogenous cellular pathways to degrade NGF mRNA and control the posttranscriptional NGF gene expression.

\section{NGF Expression in Bladder}

Several studies have reported that patients with $\mathrm{OAB}$ or IC/PBS excrete more nerve growth factor (NGF) in their urine relative to asymptomatic controls [61]. Higher expression of NGF in bladder of patients [62], with corresponding lower serum levels of NGF, makes the bladder tissue the likely source for the elevated NGF in urine [63]. Previous studies have indicated that increased levels of NGF in the bladder and bladder afferent pathways are directly involved in the emergence of hyperexcitability of C-fiber bladder sensory pathways leading to the pathology of DO and $\mathrm{OAB}$ (Figure 4) [64].

In addition, intrathecal application of NGF antibodies reduced NGF levels in bladder afferent pathways and normalized bladder/urethral function in spinal cord injured (SCI) rats [65]. Because it is likely that the major pathology of OAB is driven by NGF, targeting the intracellular synthesis of NGF molecule in bladder is a promising therapeutic alternative.

\section{NGF Expression a Drug Target}

Overexpression of NGF can be blocked either directly by antibodies [66] or by blocking the synthesis of NGF protein from mRNA [67]. Systemic administration of monoclonal human NGF antibodies (tanezumab) has been explored for therapeutic outcomes in IC/PBS patients but not without encountering safety concerns such as paresthesia, hypoesthesia, and arthralgia [66]. Generalized blockade of NGF activity at sites other than bladder by anti-NGF antibodies may not be the preferred outcome, because NGF is an essential housekeeping growth factor necessary for the survival and growth of neurons [68]. The physiological necessity of NGF action at those sites may explain the incidence of paresthesia, hypoesthesia, and arthralgia in patients treated with systemic anti-NGF antibodies [66].

9.1. Peptide Nucleic Acid (PNA). Therefore, to reduce the toxicity of systemic blockade of NGF, we sought to develop a novel intravesical therapy of $\mathrm{OAB}$ by targeting the intracellular synthesis of NGF in the urothelium. Antisense ODN needed to be able to cross cell membrane to act as a drug and negatively charged ODN will not pass through a lipid layer such as cell membranes. Bladder uptake of ODN is limited by the anionic charge and size of the ODN as well as anionic glycosaminoglycan layer of the inner bladder surface. Therefore, primary impediment to be overcome in the development of intravesical antisense therapeutics is inefficient bladder uptake of the ODN across urothelium. Previous studies showed that heparan sulfate proteoglycans expressed on cell surface act as receptors for extracellular TAT uptake [69]. Therefore, it was reasoned that GAG layer on bladder surface can facilitate bladder uptake of peptide nucleic acid PNA, if it could be conjugated with synthetic TAT peptide.

Water insoluble peptide nucleic acid targeting NGF was conjugated with cell penetrating cationic peptide TAT for intracellular delivery of antisense moiety to demonstrate efficacy in animal models. Studies showed that PNA conjugated with TAT suppressed cyclophosphamide cystitis following local instillation of antisense against NGF [67]. There was negligible uptake of peptide nucleic acid in absence of TAT conjugation. Prior to determination of in vivo efficacy of conjugate, suitable target sequence on NGF mRNA was determined by predicted folding structure and cell transfection experiments. Successful intravesical delivery of peptide 
nucleic acid in bladder at the same time of cyclophosphamide injection protected against the cystitis by blocking the rise in bladder contraction frequency and inflammation.

9.2. Phosphorothioate-Linked Analogues. Considering the difficulty and possible nonspecific toxicity of peptide nucleic acid and TAT, recent developments focused on simplifying the approach using water-soluble phosphorothioated ODN, which have an increased resistance to exo- and endonucleases for improved stability [70]. As alluded to in the above text, success of antisense therapeutics is largely dependent on the development of a delivery vehicle that can efficiently deliver antisense ODN in bladder. Preliminary studies showed that liposomes can be far better biocompatible effective carriers for local gene silencing of NGF gene in bladder cells.

Cationic liposomes and mimics have emerged as the most popular nonviral method to deliver nucleic acids in therapeutic applications. Easy and reversible complex formation of cationic liposomes with ODN at room temperature allows their use as carriers. Electrostatic attraction between the cationic lipid, DOTAP, and the polyanionic antisense ODN is responsible for the complex formation. The efficacy of liposome delivered siRNA by intravesical route has been previously demonstrated in preclinical models of bladder cancer [71]. Residence of ODN in the rat bladder after intravesical instillation was demonstrated to be longer than $24 \mathrm{~h}$ using fluorescent tagged ODN complexed with liposomes [72]. Fluorescent probe was localized in bladder urothelium cells $24 \mathrm{~h}$ following instillation. The $24 \mathrm{~h}$ residence time was also demonstrated for siRNA in mouse bladder [73]. Bladder uptake of fluorescent ODN without liposomes in normal rat bladder is poor. Previous studies have shown that very high concentration of phosphorothioated ODN can deliver ODN without liposomes to bladder cells of mice having bladder cancer [74]. The urothelium barrier may be slightly compromised in cancerous condition and the strategy of loading bladder with high dose of ODN may not work in noncancerous diseased condition of bladder with intact barrier.

In order to evaluate the efficacy of NGF antisense ODN, acetic acid infusion was used to cause a rapid rise of NGF protein levels. A single dose instillation of OND complexed with liposomes protected against bladder overactivity (BO) induced by acetic acid. Together with data of bladder uptake studies using fluorescent ODN, it is demonstrated that OND is readily available to the bladder after intravesical instillation. It has been previously reported that, within $2 \mathrm{~h}$ of exposure to irritants such as turpentine and acetic acid, there occurs a rapid rise in bladder content of NGF [75]. Later studies found that bladder responds to insults with upregulation in the genes for NGF, sE-Selectin and receptor for monocyte chemoattractant protein-1 (MCP-1) within $30 \mathrm{~min}$ of exposure to lipopolysaccharide (Figure 5) [76]. The acetic acid induced overexpression of NGF was blunted by pretreatment with NGF antisense OND with phosphorothioate linkage prior to exposure of acetic acid. The downregulation of NGF mRNA expression was in agreement with reduced protein levels and suppressed NGF-like immunoreactivity in the urothelium.
9.3. Antisense and Downstream Signalling of NGF. Drug development of intravesical antisense for NGF was also able to unmask the downstream signaling [77] involving NGF following exposure to acetic acid. Experiments supported the role of NGF as a paracrine messenger [77], which is known to activate several downstream effectors to manifest physiological and pathological signaling changes linked to it $[76,78-80]$. The bladder injury set off by acetic acid initiates the signalling cascades that upregulate the expression of NGF and other chemokines, MCP-1, CXCL-1, and CXCL10 , and prostaglandins $[76,78-80]$. As reported elsewhere, localization of chemokines within synaptic vesicles in neurons [81] is consistent with their ability to act as excitatory neurotransmitters following AA exposure.

Chemokines are one of several downstream effectors activated by NGF $[76,78-80]$ and interestingly chemokine receptors are widely expressed in neural and nonneural elements of the nociceptive pathways that are responsible for visceral and somatic pain sensation [82]. MCP-1 [83] and CXCL-10 [84] are constitutively expressed in neurons, where they participate in excitability of primary afferent neurons through transactivation of transient receptor channels and nociceptor sensitization [84]. Overexpression of NGF is likely to drive the expression of VEGF from neurons and leptin [78] from adipocytes covering neurons [85].

Cooperative expression of NGF and MCP-1 is able to induce hyperexcitability in neurons by activating TRPV1 receptor. In addition, MCP-1, CXCL-1, and CXCL-10 cause chemoattraction of monocytes, neutrophils, and lymphocytes, respectively, to mediate the bladder injury set off by acetic acid. Extravasation is an essential prerequisite for infiltration of monocytes, neutrophils, and lymphocytes, which requires the expression of adhesion molecules like E-selectin and intracellular adhesion molecule ICAM-1 [76, 86]. E-selectin is a cytokine-inducible adhesion molecule that supports the rolling and stable arrest of leukocytes on activated vascular endothelium. Expression of E-selectin has been linked to adherence of neutrophils to bladder microvascular endothelial cells and to cyclophosphamide cystitis $[87,88]$. E-selectin gene expression is activated by the NF- $\kappa \mathrm{B}$ and MAP kinase signal transduction pathways $[76,86]$.

Activation and recruitment of leukocytes to acetic acid induced bladder injury also require expression of intracellular adhesion molecule ICAM-1 [89]. ICAM-1 interacts specifically with its receptors of the integrin family to induce reversible cell-cell interactions involving adhesion. Expression of ICAM-1 was found to be increased in patients with IC/PBS and reduced in patients responding to instillation of hyaluronic acid [90]. Expression of ICAM-1 and VCAM-1 was also noted in a recent study on biopsy tissue of IC/PBS patients [91]. Increased expression of ICAM-1 subsequent to exposure with acetic acid in animal model is therefore clinically relevant.

Antisense experiments supported the earlier report that inhibition of NGF expression significantly downregulates the expression of ICAM-1 [80]. It is reported that binding of NGF to its high-affinity TrkA receptor controls the sICAM-1 expression on target cells [80]. Expression of ICAM-1 was 


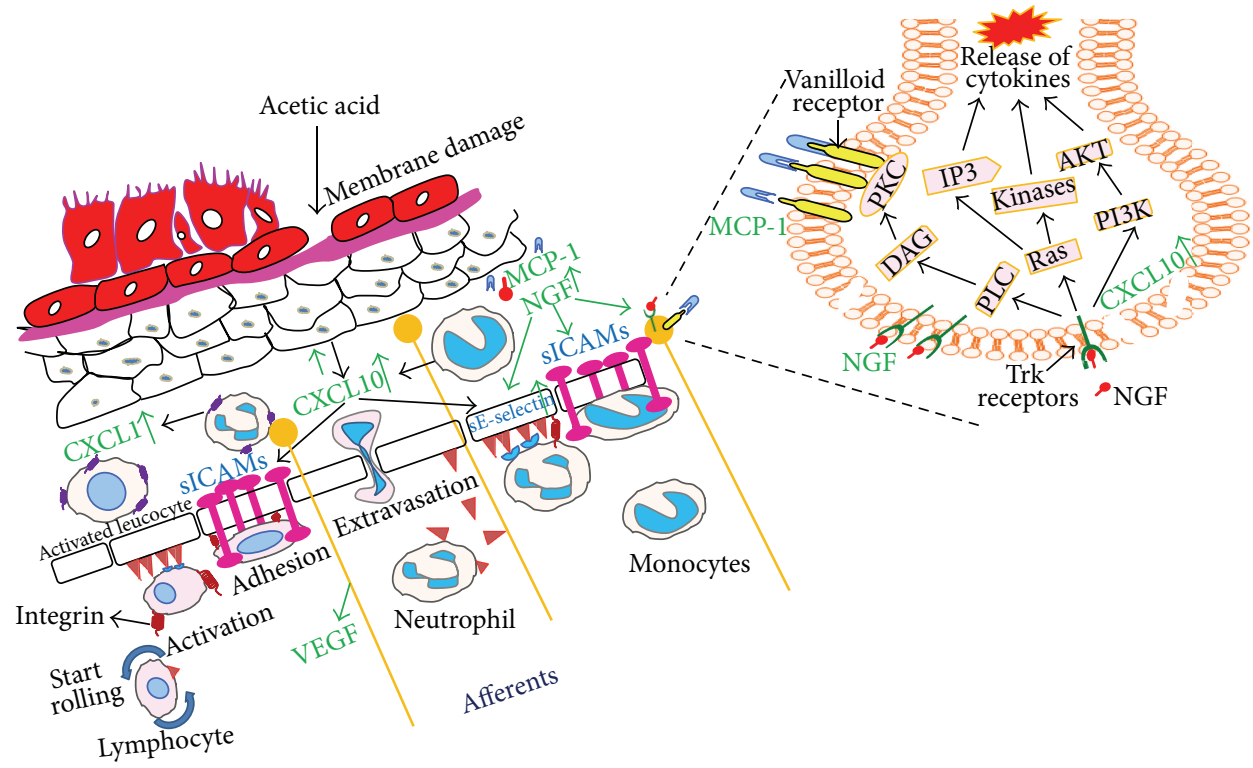

FIGURE 5: Signalling cascades induced by NGF overexpression following exposure to acetic acid. Injury from exposure to acetic sets off the signalling cascades that upregulate the expression of NGF, MCP-1, prostaglandins, CXCL-1, and CXCL-10. Overexpression of NGF drives the expression of VEGF from neurons and leptin from adipocytes covering neurons. NGF and MCP-1 also induce hyperexcitability in neurons by activating TRPV1 receptor. MCP-1, CXCL-1, and CXCL-10 cause chemoattraction of monocytes, neutrophils, and lymphocytes, which requires extravasation across endothelium from blood through the cooperation of adhesion molecules E-selectin and ICAM-1.

negatively associated with NGF expression in antisense experiments. Ultimately, expression of ICAM-1 is regulated at the level of transcription by one of several signaling cascades NF- $\kappa$ B, JAK/STAT, IFN-g (CXCL-10), AP, MAP kinase, and $\mathrm{PKC}$ [92].

Intravesical route can allow selective exposure of antisense ODN to the NGF producing cells in urothelium and avoid systemic side effects from genetic manipulation of NGF expression. Intravesical route can also prove to be cost effective given the cost of ODN or siRNA. Contrary to the goal of loss of function in bladder with antisense ODN, in recent studies liposomes have also been used to deliver ODN for gain of function in bladder [93].

\section{Imaging of Intravesical Therapy}

Drug development for DO and IC/PBS relies heavily on subjective outcomes for predicting efficacy and safety in early clinical development. Although there are many validated measurement tools used in DO and IC/PBS research, they are usually burdensome and do not capture all symptoms related to the lower urinary tract. Moreover, improvement in symptoms scores following an intervention does not always correlate with patient expectations, satisfaction, and goal achievement, which are critically important for successful management of DO and IC/PBS.

There is underdevelopment and underutilization of urine biomarkers and imaging methods for investigational drugs given by intravesical route. Overreliance on subjective impressions of patients for therapeutic response limits clinical relevance due to weak correlation with patient satisfaction and can also impede continued scientific progress in assessing study outcomes relative to symptom bother. Symptom scores may also be related to the cause of high heterogeneity in clinical response in DO and IC/PBS patients.

Imaging can offer the possibility to provide regionspecific information in situations where serum and urine assays may not reflect the true state of bladder [94-96]. Urine chemokines have been reported to be associated with symptom severity of IC/PBS patients [97]. Application of fluorescent microscopy for imaging of pelvic floor has been limited due to the issues pertaining to light absorption by tissues, scattering, and autofluorescence [98].

Recent studies have shown that dyes fluorescing in the near-infrared (NIR) band can overcome this handicap in deep-tissue imaging of experimental animals [99]. Selected NIR fluorochromes emit light with tissue penetration approaching $10-15 \mathrm{~cm}$ [100]. The light emission from probes in this spectrum encounters low background autofluorescence and minimal attenuation of signal due to light absorption by tissue components [98]. Therefore, NIR imaging yields high signal-to-noise ratios and is well suited for studying the distribution of instilled treatments in bladder (Figure 2(b)).

Preliminary studies suggest that imaging of mouse pelvic floor in NIR spectrum can be a viable option [101]. NIR imaging easily allows visualization and quantification of bladder distribution by tracing the migration of fluorescencelabeled liposomes in anaesthetized mouse. Compared with other biological assays, imaging could provide objective endpoint for patients with ulcerative cystitis to indicate its high translation potential. Other benefits of optical imaging include its relatively low cost compared with more traditional imaging systems such as MRI and PET. The instrument 
consists of two near-infrared lasers emitting at $685 \mathrm{~nm}$ and $785 \mathrm{~nm}$, camera, and novel optics.

Furthermore, preferential binding of liposomes and nanoparticles to bladder lesions of IC/PBS after instillation can be assessed by NIR imaging of bladder, where it can theoretically provide anatomically specific information about the real time status of ulcer/lesion in bladder surface or tissue abnormality [102]. Therefore, future studies can substitute a response variable that is continuous in nature instead of a subjective clinical outcome.

\section{Conclusions}

Adoption of forward-thinking approaches can achieve advancements in drug delivery systems targeted to improve pharmacotherapy of bladder diseases in the future. Latest developments in the field of nanotechnology can bring this mode of therapy from second line of treatment for refractory cases to the forefront of disease management. Liposomes are an attractive drug delivery platform by virtue of their biodegradability, biocompatibility, low toxicity, and simple and mild preparation methods.

\section{Conflict of Interests}

All authors except Dr. Michael Chancellor declare that there is no conflict of interests regarding the publication of this paper. Dr. Michael Chancellor owns stocks in the start-up liposome company, Lipella.

\section{Acknowledgments}

This work was supported by the National Institutes of Health (DK057267 and DK088836) and the Department of Defense (W81XWH-11-1-0763 and W81XWH-12-1-0565).

\section{References}

[1] J. Parkin, C. Shea, and G. R. Sant, "Intravesical dimethyl sulfoxide (DMSO) for interstitial cystitis-a practical approach," Urology, vol. 49, no. 5, pp. 105-107, 1997.

[2] C. Dowson, J. Watkins, M. S. Khan, P. Dasgupta, and A. Sahai, "Repeated botulinum toxin type A injections for refractory overactive bladder: medium-term outcomes, safety profile, and discontinuation rates," European Urology, vol. 61, no. 4, pp. 834839, 2012.

[3] J. Kaufman, V. Tyagi, M. Anthony, M. B. Chancellor, and P. Tyagi, "State of the art in intravesical therapy for lower urinary tract symptoms," Reviews in Urology, vol. 12, pp. e181-e189, 2010.

[4] N. Yoshimura and M. B. Chancellor, "Current and future pharmacological treatment for overactive bladder," Journal of Urology, vol. 168, no. 5, pp. 1897-1913, 2002.

[5] K. A. Killinger, J. A. Boura, and K. M. Peters, "Pain in interstitial cystitis/bladder pain syndrome: do characteristics differ in ulcerative and non-ulcerative subtypes?" International Urogynecology Journal, vol. 24, no. 8, pp. 1295-1301, 2013.

[6] J. C. Nickel, P. Hanno, K. Kumar, and H. Thomas, "Second multicenter, randomized, double-blind, parallel-group evaluation of effectiveness and safety of intravesical sodium chondroitin sulfate compared with inactive vehicle control in subjects with interstitial cystitis/bladder pain syndrome," Urology, vol. 79, no. 6, pp. 1220-1225, 2012.

[7] P. M. Hanno, "Analysis of long-term elmiron therapy for interstitial cystitis," Urology, vol. 49, no. 5, pp. 93-99, 1997.

[8] A. Giannantoni, V. Bini, R. Dmochowski et al., "Reply to Claus Riedl's letter to the editor re: antonella Giannantoni, Vittorio Bini, Roger Dmochowski, et al. Contemporary management of the painful bladder: a systematic review," European Urology, vol. 61, no. 5, pp. 29-53, 2012.

[9] M. C. Lai, Y. C. Kuo, and H. C. Kuo, "Intravesical hyaluronic acid for interstitial cystitis/painful bladder syndrome: a comparative randomized assessment of different regimens," International Journal of Urology, vol. 20, pp. 203-207, 2013.

[10] J. Eldrup, J. Thorup, and S. L. Nielsen, "Permeability and ultrastructure of human bladder epithelium," British Journal of Urology, vol. 55, no. 5, pp. 488-492, 1983.

[11] C. L. Parsons, D. Boychuk, S. Jones, R. Hurst, and H. Callahan, "Bladder surface glycosaminoglycans: an epithelial permeability barrier," Journal of Urology, vol. 143, no. 1, pp. 139-142, 1990.

[12] Y. Kim, N. Yoshimura, H. Masuda, F. De Miguel, and M. B. Chancellor, "Antimuscarinic agents exhibit local inhibitory effects on muscarinic receptors in bladder-afferent pathways," Urology, vol. 65, no. 2, pp. 238-242, 2005.

[13] V. Tyagi, B. J. Philips, R. Su et al., "Differential expression of functional cannabinoid receptors in human bladder detrusor and urothelium," Journal of Urology, vol. 181, no. 4, pp. 1932$1938,2009$.

[14] B. J. Philips, M. C. Smaldone, V. L. Erickson, N. Yoshimura, M. B. Chancellor, and P. Tyagi, "Differential expression of neurokinin receptor subtypes in urothelium and detrusor of human bladder," Journal of Urology, vol. 179, article 354, 2008.

[15] S. A. Baker, G. W. Hennig, J. Han, F. C. Britton, T. K. Smith, and S. D. Koh, "Methionine and its derivatives increase bladder excitability by inhibiting stretch-dependent K+ channels," British Journal of Pharmacology, vol. 153, no. 6, pp. 1259-1271, 2008.

[16] J. M. Beckel, A. Kanai, S.-J. Lee, W. C. De Groat, and L. A. Birder, "Expression of functional nicotinic acetylcholine receptors in rat urinary bladder epithelial cells," American Journal of Physiology-Renal Physiology, vol. 290, no. 1, pp. F103-F110, 2006.

[17] L. A. Birder, A. J. Kanai, W. C. De Groat et al., "Vanilloid receptor expression suggests a sensory role for urinary bladder epithelial cells," Proceedings of the National Academy of Sciences of the United States of America, vol. 98, no. 23, pp. 13396-13401, 2001.

[18] P. Tyagi, C. A. Thomas, N. Yoshimura, and M. B. Chancellor, "Investigations into the presence of functional $ß 1, \beta 2$ and $B 3$ adrenoceptors in urothelium and detrusor of human bladder," International Brazilian Journal of Urology, vol. 35, no. 1, pp. 7683, 2009.

[19] A. T. Hanna-Mitchell, J. M. Beckel, S. Barbadora, A. J. Kanai, W. C. de Groat, and L. A. Birder, "Non-neuronal acetylcholine and urinary bladder urothelium," Life Sciences, vol. 80, no. 24-25, pp. 2298-2302, 2007.

[20] C. P. Smith, D. A. Gangitano, A. Munoz et al., "Botulinum toxin type A normalizes alterations in urothelial ATP and NO release induced by chronic spinal cord injury," Neurochemistry International, vol. 52, no. 6, pp. 1068-1075, 2008.

[21] Y.-C. Chuang, C. A. Thomas, S. Tyagi, N. Yoshimura, P. Tyagi, and M. B. Chancellor, "Human urine with solifenacin 
intake but not tolterodine or darifenacin intake blocks detrusor overactivity," International Urogynecology Journal and Pelvic Floor Dysfunction, vol. 19, no. 10, pp. 1353-1357, 2008.

[22] Y. Kim, N. Yoshimura, H. Masuda, F. D. Miguel, and M. B. Chancellor, "Intravesical instillation of human urine after oral administration of trospium, tolterodine and oxybutynin in a rat model of detrusor overactivity," BJU International, vol. 97, no. 2, pp. 400-403, 2006.

[23] S. Tyagi, P. Tyagi, S. Van-le, N. Yoshimura, M. B. Chancellor, and F. de Miguel, "Qualitative and quantitative expression profile of muscarinic receptors in human urothelium and detrusor," Journal of Urology, vol. 176, no. 4, pp. 1673-1678, 2006.

[24] G. Gregoriadis and B. E. Ryman, "Liposomes as carriers of enzymes or drugs: a new approach to the treatment of storage diseases," Biochemical Journal, vol. 124, no. 5, p. 58, 1971.

[25] G. Gregoriadis, S. Jain, I. Papaioannou, and P. Laing, "Improving the therapeutic efficacy of peptides and proteins: a role for polysialic acids," International Journal of Pharmaceutics, vol. 300, no. 1-2, pp. 125-130, 2005.

[26] P. Sapra, P. Tyagi, and T. M. Allen, "Ligand-targeted liposomes for cancer treatment," Current Drug Delivery, vol. 2, no. 4, pp. 369-381, 2005.

[27] G. Gregoriadis, G. Dapergolas, and E. D. Neerunjun, "Penetration of target areas in the rat by liposome associated agents administered parenterally and intragastrically," Biochemical Society Transactions, vol. 4, no. 2, pp. 256-259, 1976.

[28] G. Gregoriadis, "Engineering liposomes for drug delivery: progress and problems," Trends in Biotechnology, vol. 13, no. 12, pp. 527-537, 1995.

[29] G. Gregoriadis and A. C. Allison, "Entrapment of proteins in liposomes prevents allergic reactions in pre immunised mice," FEBS Letters, vol. 45, no. 1, pp. 71-74, 1974.

[30] S. Lee, S. Dausch, C. Maierhofer, and D. Dausch, "A new therapy concept with a liposome eye spray for the treatment of the 'dry eye," Klinische Monatsblatter fur Augenheilkunde, vol. 221, no. 10, pp. 825-836, 2004.

[31] D. Dausch, S. Lee, S. Dausch, J. C. Kim, G. Schwert, and W. Michelson, "Comparative study of treatment of the dry eye syndrome due to disturbances of the tear film lipid layer with lipid-containing tear substitutes: efficacy of lipid-containing tear substitutes," Klinische Monatsblatter fur Augenheilkunde, vol. 223, no. 12, pp. 974-983, 2006.

[32] S. Ebrahim, G. A. Peyman, and P. J. Lee, "Applications of liposomes in ophthalmology," Survey of Ophthalmology, vol. 50, no. 2, pp. 167-182, 2005.

[33] J. Nirmal, P. Tyagi, L. Dang et al., "Endocytosis uptake of liposomes in urothelium cells detected by transmission electron microscopy," The Journal of Urology, vol. 187, article e15, 2012.

[34] D. N. Frangos, J. J. Killion, D. Fan, R. Fishbeck, A. C. Von Eschenbach, and I. J. Fidler, "The development of liposomes containing interferon alpha for the intravesical therapy of human superficial bladder cancer," Journal of Urology, vol. 143, no. 6, pp. 1252-1266, 1990.

[35] J. W. Johnson, R. Nayar, J. J. Killion, A. C. Von Eschenbach, and I. J. Fidler, "Binding of liposomes to human bladder tumor epithelial cell lines: implications for an intravesical drug delivery system for the treatment of bladder cancer," Selective Cancer Therapeutics, vol. 5, no. 4, pp. 147-155, 1989.

[36] Y.-C. Chuang, M. B. Chancellor, S. Seki et al., "Intravesical protamine sulfate and potassium chloride as a model for bladder hyperactivity," Urology, vol. 61, no. 3, pp. 664-670, 2003.
[37] J. Kaufman, P. Tyagi, and M. B. Chancellor, "Intravesical liposomal (Lp08) instillation protects bladder urothelium from chemical irritation," The Journal of Urology, vol. 181, article 539, 2009.

[38] P. Tyagi, M. B. Chancellor, Z. Li et al., "Urodynamic and immunohistochemical evaluation of intravesical capsaicin delivery using thermosensitive hydrogel and liposomes," Journal of Urology, vol. 171, no. 1, pp. 483-489, 2004.

[39] M. O. Fraser, Y.-C. Chuang, P. Tyagi et al., "Intravesical liposome administration - a novel treatment for hyperactive bladder in the rat," Urology, vol. 61, no. 3, pp. 656-663, 2003.

[40] P. Tyagi, M. Chancellor, N. Yoshimura, and L. Huang, "Activity of different phospholipids in attenuating hyperactivity in bladder irritation," BJU International, vol. 101, no. 5, pp. 627-632, 2008.

[41] Y. Sun and T. C. Chai, "Effects of dimethyl sulphoxide and heparin on stretch-activated ATP release by bladder urothelial cells from patients with interstitial cystitis," BJU International, vol. 90, no. 4, pp. 381-385, 2002.

[42] J. J. Bade, "A placebo-controlled study of intravesical pentosanpolysulphate for the treatment of interstitial cystitis," British Journal of Urology, vol. 79, no. 2, pp. 168-171, 1997.

[43] P. Tyagi, V. C. Hsieh, N. Yoshimura, J. Kaufman, and M. B. Chancellor, "Instillation of liposomes vs dimethyl sulphoxide or pentosan polysulphate for reducing bladder hyperactivity," $B J U$ International, vol. 104, no. 11, pp. 1689-1692, 2009.

[44] W.-C. Lee, C.-T. Chien, H.-J. Yu, and S.-W. Lee, "Bladder dysfunction in rats with metabolic syndrome induced by longterm fructose feeding," Journal of Urology, vol. 179, no. 6, pp. 2470-2476, 2008.

[45] J. I. Gillespie, G. A. Van Koeveringe, S. G. De Wachter, and J. De Vente, "On the origins of the sensory output from the bladder: the concept of afferent noise," BJU International, vol. 103, no. 10, pp. 1324-1333, 2009.

[46] W. C. Lee, P. H. Chiang, Y. L. Tain, C. C. Wu, and Y. C. Chuang, "Sensory dysfunction of bladder mucosa and bladder oversensitivity in a rat model of metabolic syndrome," PloS ONE, vol. 7, Article ID e45578, 2012.

[47] Y.-C. Chuang, W.-C. Lee, W.-C. Lee, and P.-H. Chiang, "Intravesical liposome versus oral pentosan polysulfate for interstitial cystitis/painful bladder syndrome," Journal of Urology, vol. 182, no. 4, pp. 1393-1400, 2009.

[48] W.-C. Lee, Y.-C. Chuang, W.-C. Lee, and P.-H. Chiang, "Safety and dose flexibility clinical evaluation of intravesical liposome in patients with interstitial cystitis or painful bladder syndrome," Kaohsiung Journal of Medical Sciences, vol. 27, no. 10, pp. 437-440, 2011.

[49] S. T. Truschel, E. Wang, W. G. Ruiz et al., "Stretch-regulated exocytosis/endocytosis in bladder umbrella cells," Molecular Biology of the Cell, vol. 13, no. 3, pp. 830-846, 2002.

[50] M. B. Chancellor and W. C. De Groat, "Intravesical capsaicin and resiniferatoxin therapy: spicing up the ways to treat the overactive bladder," Journal of Urology, vol. 162, no. 1, pp. 3-11, 1999.

[51] D. S. Byrne, A. Das, J. Sedor et al., "Effect of intravesical capsaicin and vehicle on bladder integrity in control and spinal cord injured rats," Journal of Urology, vol. 159, no. 3, pp. 10741078, 1998.

[52] M. Mandal and K.-D. Lee, "Listeriolysin O-liposome-mediated cytosolic delivery of macromolecule antigen in vivo: enhancement of antigen-specific cytotoxic $\mathrm{T}$ lymphocyte frequency, 
activity, and tumor protection," Biochimica et Biophysica Acta, vol. 1563, no. 1-2, pp. 7-17, 2002.

[53] Y.-C. Chuang, P. Tyagi, C.-C. Huang et al., "Urodynamic and immunohistochemical evaluation of intravesical botulinum toxin a delivery using liposomes," Journal of Urology, vol. 182, no. 2, pp. 786-792, 2009.

[54] Y.-C. Chuang, N. Yoshimura, C.-C. Huang, P.-H. Chiang, and M. B. Chancellor, "Intravesical botulinum toxin a administration produces analgesia against acetic acid induced bladder pain responses in rats," Journal of Urology, vol. 172, no. 4, pp. 15291532, 2004.

[55] S. P. Petrou, A. S. Parker, J. E. Crook, A. Rogers, D. MetzKudashick, and D. D. Thiel, "Botulinum A toxin/dimethyl sulfoxide bladder instillations for women with refractory idiopathic detrusor overactivity: a phase 1/2 study," Mayo Clinic Proceedings, vol. 84, no. 8, pp. 702-706, 2009.

[56] P. Caccin, O. Rossetto, M. Rigoni, E. Johnson, G. Schiavo, and C. Montecucco, "VAMP/synaptobrevin cleavage by tetanus and botulinum neurotoxins is strongly enhanced by acidic liposomes," FEBS Letters, vol. 542, no. 1-3, pp. 132-136, 2003.

[57] M. L. Stephenson and P. C. Zamecnik, "Inhibition of Rous sarcoma viral RNA translation by a specific oligodeoxyribonucleotide," Proceedings of the National Academy of Sciences of the United States of America, vol. 75, no. 1, pp. 285-288, 1978.

[58] H. Dadgostar and N. Waheed, "The evolving role of vascular endothelial growth factor inhibitors in the treatment of neovascular age-related macular degeneration," Eye, vol. 22, no. 6, pp. 761-767, 2008.

[59] C. Gebhard, G. Huard, E. A. Kritikou, and J. C. Tardif, "Apolipoprotein B antisense inhibition-update on mipomersen," Current Pharmaceutical Design, vol. 919, no. 17, pp. 31323142, 2013.

[60] T. Yokota, E. Hoffman, and S. Takeda, "Antisense oligomediated multiple exon skipping in a dog model of duchenne muscular dystrophy," Methods in Molecular Biology, vol. 709, pp. 299-312, 2011.

[61] B. L. Jacobs, M. C. Smaldone, V. Tyagi et al., "Increased nerve growth factor in neurogenic overactive bladder and interstitial cystitis patients," The Canadian Journal of Urology, vol. 17, no. 1, pp. 4989-4994, 2010.

[62] H.-T. Liu and H.-C. Kuo, "Intravesical botulinum toxin A injections plus hydrodistension can reduce nerve growth factor production and control bladder pain in interstitial cystitis," Urology, vol. 70, no. 3, pp. 463-468, 2007.

[63] H. T. Liu and H. C. Kuo, "Increased urine and serum nerve growth factor levels in interstitial cystitis suggest chronic inflammation is involved in the pathogenesis of disease," PloS ONE, vol. 7, Article ID e44687, 2012.

[64] N. Yoshimura, N. E. Bennett, Y. Hayashi et al., "Bladder overactivity and hyperexcitability of bladder afferent neurons after intrathecal delivery of nerve growth factor in rats," Journal of Neuroscience, vol. 26, no. 42, pp. 10847-10855, 2006.

[65] S. Seki, K. Sasaki, Y. Igawa et al., "Suppression of detrusorsphincter dyssynergia by immunoneutralization of nerve growth factor in lumbosacral spinal cord in spinal cord injured rats," Journal of Urology, vol. 171, no. 1, pp. 478-482, 2004.

[66] R. J. Evans, R. M. Moldwin, N. Cossons, A. Darekar, I. W. Mills, and D. Scholfield, "Proof of concept trial of tanezumab for the treatment of symptoms associated with interstitial cystitis," Journal of Urology, vol. 185, no. 5, pp. 1716-1721, 2011.
[67] P. Tyagi, R. Banerjee, S. Basu, N. Yoshimura, M. Chancellor, and L. Huang, "Intravesical antisense therapy for cystitis using TATpeptide nucleic acid conjugates," Molecular Pharmaceutics, vol. 3, no. 4, pp. 398-406, 2006.

[68] D. C. Molliver, D. E. Wright, M. L. Leitner et al., "IB4-binding DRG neurons switch from NGF to GDNF dependence in early postnatal life," Neuron, vol. 19, no. 4, pp. 849-861, 1997.

[69] M. Tyagi, M. Rusnati, M. Presta, and M. Giacca, "Internalization of HIV-1 tat requires cell surface heparan sulfate proteoglycans," Journal of Biological Chemistry, vol. 276, no. 5, pp. 3254-3261, 2001.

[70] E. Uhlmann, A. Ryte, and A. Peyman, "Studies on the mechanism of stabilization of partially phosphorothioated oligonucleotides against nucleolytic degradation," Antisense and Nucleic Acid Drug Development, vol. 7, no. 4, pp. 345-350, 1997.

[71] M. Nogawa, T. Yuasa, S. Kimura et al., "Intravesical administration of small interfering RNA targeting PLK-1 successfully prevents the growth of bladder cancer," Journal of Clinical Investigation, vol. 115, no. 4, pp. 978-985, 2005.

[72] M. Kashyap, N. Kawamorita, V. Tyagi et al., "Downregulation of NGF expression in the bladder by antisense oligoucleotides as new treatment for overactive bladder," Journal of Urology, vol. 27190, no. 2, pp. 757-764, 2013.

[73] C.-J. Arum, Y. Kodama, N. Rolim et al., "A rat model of intravesical delivery of small interfering RNA for studying urinary carcinoma," World Journal of Urology, vol. 28, no. 4, pp. 479-485, 2010.

[74] C. E. Blietz, B. Thode, M. Hauses et al., "In vivo studies on the availability and toxicity of antisense oligonucleotides in bladder cancer," In Vivo, vol. 23, no. 1, pp. 13-19, 2009.

[75] D. Oddiah, P. Anand, S. B. McMahon, and M. Rattray, "Rapid increase of NGF, BDNF and NT-3 mRNAs in inflamed bladder," NeuroReport, vol. 9, no. 7, pp. 1455-1458, 1998.

[76] M. R. Saban, H. Hellmich, N. B. Nguyen, J. Winston, T. G. Hammond, and R. Saban, "Time course of LPS-induced gene expression in a mouse model of genitourinary inflammation," Physiol Genomics, vol. 5, no. 3, pp. 147-160, 2001.

[77] B. Schnegelsberg, T. T. Sun, G. Cain et al., "Overexpression of NGF in mouse urothelium leads to neuronal hyperinnervation, pelvic sensitivity, and changes in urinary bladder function," The American Journal of Physiology -Regulatory, Integrative and Comparative Physiology, vol. 298, no. 5, pp. R534-R547, 2010.

[78] S. Cardenas, M. Scuri, L. Samsell et al., "Neurotrophic and neuroimmune responses to early-life Pseudomonas aeruginosa infection in rat lungs," American Journal of Physiology-Lung Cellular and Molecular Physiology, vol. 299, no. 3, pp. L334L344, 2010.

[79] K. Nakamura, F. Tan, Z. Li, and C. J. Thiele, "NGF activation of TrkA induces vascular endothelial growth factor expression via induction of hypoxia-inducible factor- $1 \alpha$," Molecular and Cellular Neuroscience, vol. 46, no. 2, pp. 498-506, 2011.

[80] S. Othumpangat, M. Regier, and G. Piedimonte, "Nerve growth factor modulates human rhinovirus infection in airway epithelial cells by controlling ICAM-1 expression," American Journal of Physiology Lung Cellular and Molecular Physiology, vol. 15302, pp. L1057-L1066, 2012.

[81] H. Jung, P. T. Toth, F. A. White, and R. J. Miller, "Monocyte chemoattractant protein-1 functions as a neuromodulator in dorsal root ganglia neurons," Journal of Neurochemistry, vol. 104, no. 1, pp. 254-263, 2008.

[82] F. A. White, H. Jung, and R. J. Miller, "Chemokines and the pathophysiology of neuropathic pain," Proceedings of the 
National Academy of Sciences of the United States of America, vol. 104, no. 51, pp. 20151-20158, 2007.

[83] G. Banisadr, R.-D. Gosselin, P. Mechighel, W. Rostène, P. Kitabgi, and S. M. Parsadaniantz, "Constitutive neuronal expression of CCR2 chemokine receptor and its colocalization with neurotransmitters in normal rat brain: functional effect of MCP-1/CCL2 on calcium mobilization in primary cultured neurons," Journal of Comparative Neurology, vol. 492, no. 2, pp. 178-192, 2005.

[84] S. Bhangoo, D. Ren, R. J. Miller et al., "Delayed functional expression of neuronal chemokine receptors following focal nerve demyelination in the rat: a mechanism for the development of chronic sensitization of peripheral nociceptors," Molecular Pain, vol. 3, article 38, 2007.

[85] T. Maeda, N. Kiguchi, Y. Kobayashi, T. Ikuta, M. Ozaki, and S. Kishioka, "Leptin derived from adipocytes in injured peripheral nerves facilitates development of neuropathic pain via macrophage stimulation," Proceedings of the National Academy of Sciences of the United States of America, vol. 106, no. 31, pp. 13076-13081, 2009.

[86] H. Kajiwara, M. Yasuda, N. Kumaki, T. Shibayama, and Y. Osamura, "Expression of carbohydrate antigens (SSEA-1, SialylLewis X, DU-PAN-2 and CA19-9) and E-selectin in urothelial carcinoma of the renal pelvis, ureter, and urinary bladder," Tokai Journal of Experimental and Clinical Medicine, vol. 30, no. 3, pp. 177-182, 2005.

[87] A. M. S. Assreuy, G. J. Martins, M. E. F. Moreira et al., "Prevention of cyclophosphamide-induced hemorrhagic cystitis by glucose- mannose binding plant lectins," Journal of Urology, vol. 161, no. 6, pp. 1988-1993, 1999.

[88] S. M. Vinson, A. Rickard, J. S. Ryerse, and J. McHowat, "Neutrophil adherence to bladder microvascular endothelial cells following platelet-activating factor acetylhydrolase inhibition," Journal of Pharmacology and Experimental Therapeutics, vol. 314, no. 3, pp. 1241-1247, 2005.

[89] M. Green, A. Filippou, G. Sant, and T. C. Theoharides, "Expression of intercellular adhesion molecules in the bladder of patients with interstitial cystitis," Urology, vol. 63, no. 4, pp. 688693, 2004.

[90] M. Leppilahti, P. Hellström, and T. L. J. Tammela, "Effect of diagnostic hydrodistension and four intravesical hyaluronic acid instillations on bladder ICAM-1 intensity and association of ICAM-1 intensity with clinical response in patients with interstitial cystitis," Urology, vol. 60, no. 1, pp. 46-51, 2002.

[91] A. T. Corcoran, N. Yoshimura, V. Tyagi, B. Jacobs, W. Leng, and P. Tyagi, "Mapping the cytokine profile of painful bladder syndrome/interstitial cystitis in human bladder and urine specimens," World Journal of Urology, vol. 31, no. 1, pp. 241-246, 2013.

[92] S. Garrean, X.-P. Gao, V. Brovkovych et al., "Caveolin-1 regulates NF- $\kappa \mathrm{B}$ activation and lung inflammatory response to sepsis induced by lipopolysaccharide," Journal of Immunology, vol. 177, no. 7, pp. 4853-4860, 2006.

[93] M. R. Kang, G. Yang, R. F. Place et al., "Intravesical delivery of small activating RNA formulated into lipid nanoparticles inhibits orthotopic bladder tumor growth," Cancer Research, vol. 172, pp. 5069-5079, 2012.

[94] P. Tyagi, D. Barclay, R. Zamora et al., "Urine cytokines suggest an inflammatory response in the overactive bladder: a pilot study," International Urology and Nephrology, vol. 42, no. 3, pp. 629-635, 2010.
[95] P. Tyagi, B. L. Jacobs, D. Barcaly et al., "Urine levels of inflammatory chemokines can be novel biomarkers for the overactive bladder," The Journal of Urology, vol. 181, article 588, 2009.

[96] P. Tyagi, V. Tyagi, D. Bui et al., "Discrimination Of OAB from IC/PBS by multivariate data modeling of urinary proteins," The Journal of Urology, vol. 183, pp. e614-e6e5, 2010.

[97] P. Tyagi, D. Nikolavsky, Y. Vodovotz et al., "Urine levels of selected chemokines positively correlate with lower bladder capacity and psychometric scores in Ic/Pbs patients," The Journal of Urology, vol. 181, article 21, 2009.

[98] R. Weissleder and V. Ntziachristos, "Shedding light onto live molecular targets," Nature Medicine, vol. 9, no. 1, pp. 123-128, 2003.

[99] C. Bremer, V. Ntziachristos, and R. Weissleder, "Optical-based molecular imaging: contrast agents and potential medical applications," European Radiology, vol. 13, no. 2, pp. 231-243, 2003.

[100] U. Mahmood and R. Weissleder, "Near-infrared optical imaging of proteases in cancer," Molecular Cancer Therapeutics, vol. 2, pp. 489-496, 2003.

[101] J. Kaufman, H. Hensley, J. Jacobs et al., "Non-invasive imaging of near infrafred dye labeled liposomes facilitates evaluation of bioresidence time," The Journal of Urology, vol. 183, article e628, 2010.

[102] Y.-X. J. Wang, "Medical imaging in pharmaceutical clinical trials: what radiologists should know," Clinical Radiology, vol. 60, no. 10, pp. 1051-1057, 2005. 

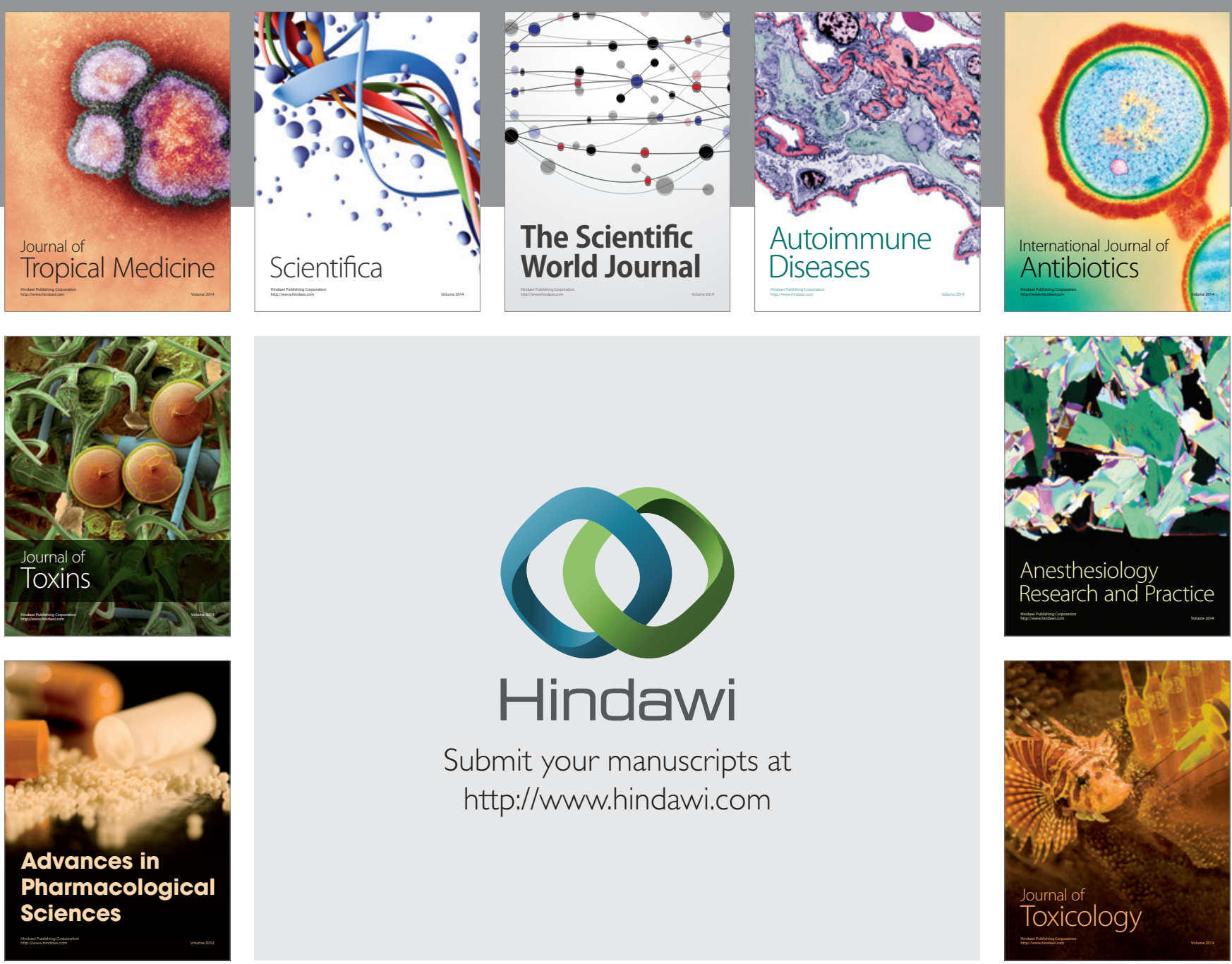

\section{Hindawi}

Submit your manuscripts at

http://www.hindawi.com
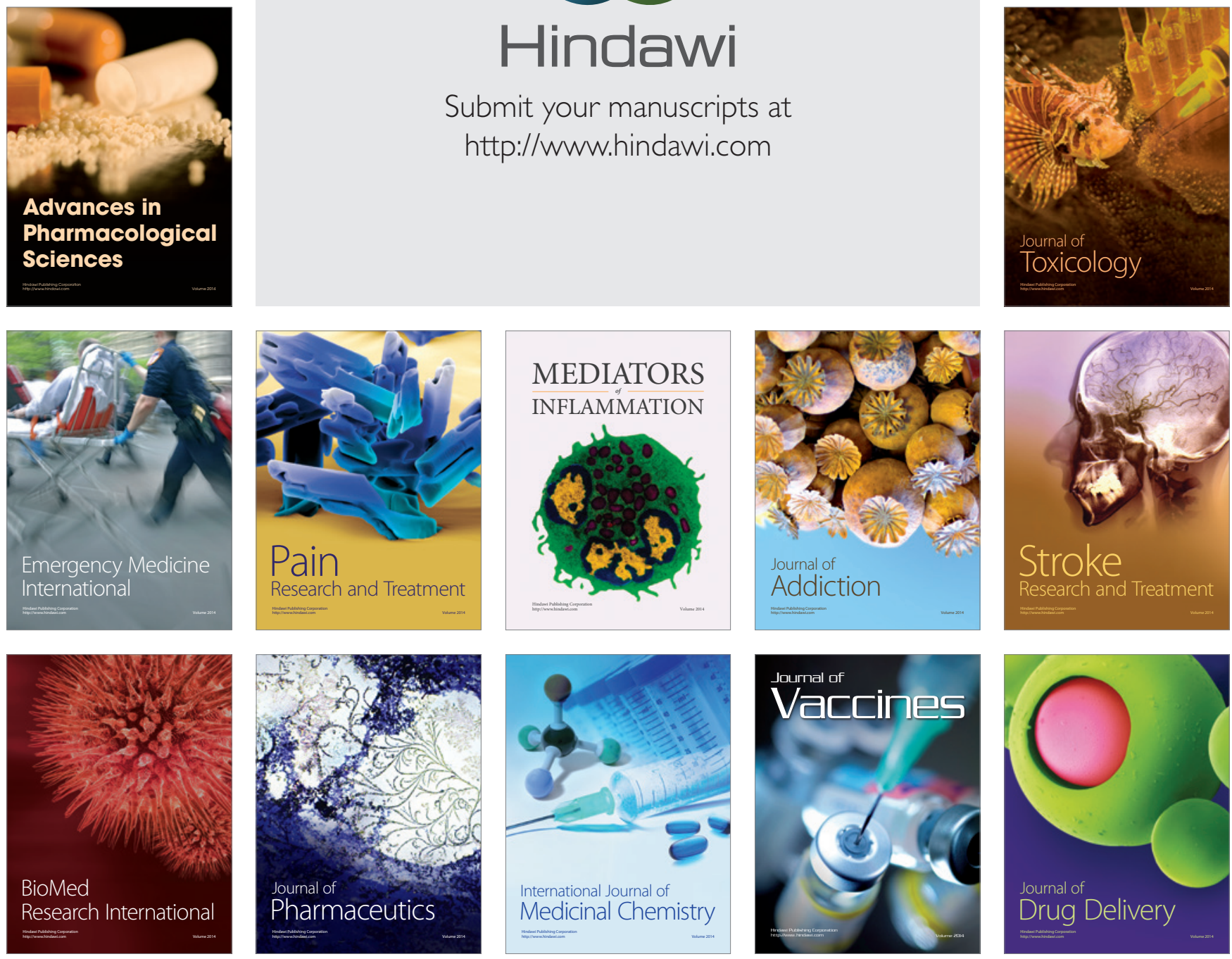